\title{
Do wearable alcohol-based handrub dispensers increase hand hygiene compliance? - a mixed-methods study
}

\author{
Jonas Keller ${ }^{1 \dagger}$, Aline Wolfensberger ${ }^{1 *+} \mathbb{D}$, Lauren Clack', Stefan P. Kuster ${ }^{1}$, Mesida Dunic $^{1}$, Doris Eis ${ }^{2}$,
} Yvonne Flammer ${ }^{1,3}$, Dagmar I. Keller ${ }^{2}$ and Hugo Sax

\begin{abstract}
Background: Hand Hygiene $(\mathrm{HH})$ compliance was shown to be poor in several studies. Improving the availability of alcohol-based hand rub (ABHR) is a cornerstone for increasing $\mathrm{HH}$ compliance.

Methods: In this study, we introduced wearable dispensers for ABHR in an Emergency Department (ED) well equipped with mounted ABHR dispensers and accompanied this single-modal intervention by a quasi-experimental mixed-method study. The study was performed in the ED of the University Hospital Zurich, Switzerland, a 950-bed tertiary teaching hospital. During a five-week baseline period and a seven-week intervention period, we observed $\mathrm{HH}$ compliance according to the WHO 'Five Moments' concept, measured ABHR consumption, and investigated perceived ABHR availability, self-reported $\mathrm{HH}$ compliance and knowledge of $\mathrm{HH}$ indications by questionnaire. Multivariable logistic regression was used to identify independent determinants for $\mathrm{HH}$ compliance. In addition, semi-structured interviews were conducted and thematically analyzed to assess barriers and facilitators for the use of the newly introduced dispensers.
\end{abstract}

Results: Across 811 observed HH opportunities, the HH compliance for all moments was 56\% (95\% confidence interval $(\mathrm{Cl}), 51-62 \%)$ during baseline and $64 \%(\mathrm{Cl}, 59-68 \%)$ during intervention period, respectively. In the multivariable analysis adjusted for sex, profession, and WHO HH moment, there was no difference in $\mathrm{HH}$ compliance between baseline and intervention (adjusted Odds ratio: 1.22 (0.89-1.66), $p=0$. 22), No significant changes were observed in consumption and perceived availability of ABHR. During intervention, 7.5\% ABHR was consumed using wearable dispensers. HCP perceived wearable dispensers as unnecessary since mounted dispensers were readily accessible. Poor ergonomic design of the wearable dispenser emerged as a main barrier, especially its lid and fastening mechanism. Interviewees identified two ideal situations for wearable dispensers, HCP who accompany patients from ED to other wards, and HCP approaching a patient from a non-patient areas in the ED such as the central working station or the meeting room.

Conclusion: The introduction of wearable dispensers did not increase observed hand hygiene compliance or ABHR consumption in an ED already well equipped with mounted dispensers. For broader acceptance and use, wearable dispensers might benefit from an optimized ergonomic design.

Keywords: Hand hygiene, Compliance, Wearable dispensers, Pocket dispensers, Clip on dispensers, Emergency room, Availability, Point of care

\footnotetext{
* Correspondence: aline.wolfensberger@usz.ch

${ }^{\dagger}$ Jonas Keller and Aline Wolfensberger contributed equally to this work.

'Division of Infectious Diseases and Hospital Epidemiology, University

Hospital Zurich, University of Zurich, Rämistrasse 100, CH-8091 Zurich,

Switzerland

Full list of author information is available at the end of the article
}

(c) The Author(s). 2018 Open Access This article is distributed under the terms of the Creative Commons Attribution 4.0 International License (http://creativecommons.org/licenses/by/4.0/), which permits unrestricted use, distribution, and reproduction in any medium, provided you give appropriate credit to the original author(s) and the source, provide a link to the Creative Commons license, and indicate if changes were made. The Creative Commons Public Domain Dedication waiver (http://creativecommons.org/publicdomain/zero/1.0/) applies to the data made available in this article, unless otherwise stated. 


\section{Background}

Despite significant advances in infection control, healthcare-associated infections represent a major challenge to modern medicine [1]. Appropriate hand hygiene $(\mathrm{HH})$ is considered crucial to reduce the transmission of nosocomial pathogens and helps to prevent hospital-acquired infections [2, 3]. However, $\mathrm{HH}$ compliance has been shown to be poor in a multitude of studies $[4,5]$. Data about $\mathrm{HH}$ compliance in Emergency Departments (ED) is limited, and results vary greatly [6]. ED physicians had a higher risk for non-adherence to $\mathrm{HH}$ compared to physicians working in other departments [7]. The mean rate of $\mathrm{HH}$ indications is higher in the ED than in medical or surgical wards [8], and high workload has been identified as a risk factor for low $\mathrm{HH}$ compliance [5].

To improve $\mathrm{HH}$ compliance, WHO names two strategies with known effectiveness: introducing widely accessible alcohol based hand rub (ABHR), and multifaceted interventions [4]. Again, in multifaceted approaches, improving the availability of $\mathrm{ABHR}$ is often an element of success [7]. Providing ABHR at the 'point of care' - requiring ABHR to be easily accessible and as close as possible (e.g. within arm's reach), where patient care or treatment is taking place - is a cornerstone of the WHO strategy to improve $\mathrm{HH}$ compliance [4]. Accessibility can be achieved by introducing wearable dispensers with ABHR $[9,10]$. But, in a single intervention study in 2008, Haas et al. showed that availability of wearable ABHR dispensers alone was not associated with a significant improvement in $\mathrm{HH}$ compliance in an ED [11].

For many years, ED personnel in our hospital expressed the wish to benefit from wearable dispensers. All wards of the University Hospital Zurich (UHZ), including the ED, are well equipped with mounted ABHR dispensers in close vicinity of patients, and up to this study, wearable dispensers were only available for staff in a few selected wards, e.g. in neonatology. In spring 2016, the infection prevention and control (IPC) team decided to meet the ED's wish for wearable dispensers. The introduction was accompanied by a mixed-method study to investigate $\mathrm{HH}$ compliance, ABHR consumption, and the attitude of healthcare providers (HCP) towards wearable dispensers.

\section{Methods}

\section{Study setting and population}

The study was conducted between April and June 2016 at the ED of the UHZ, Switzerland. The UHZ is a 950-bed tertiary hospital covering all medical specialties except pediatrics and orthopedics. The ED holds 17 beds, and a mean of 44'000 patients are admitted to the ED yearly. The ED staff consists of 100 nurses, 13 staff emergency physicians, 25 medical interns, and various other professions (e.g. maintenance and nursing assistants). Non-ED consulting physicians and surgeons regularly visiting the ED. The study population for $\mathrm{HH}$ observation and interviews consisted of ED staff only, ABHR consumption was measured overall, thus including also HCP visiting the ER. The ED has an open floor plan with a central nursing and working station, and single patient bays separated by privacy curtains. Mounted dispensers are available in or immediately outside every patient room/bay. In total, there are 34 wall-mounted or table-top dispensers available in close proximity, i.e. below $2 \mathrm{~m}$, of each patient bed. Additional dispensers exist in the staff lounge, storage rooms, and restrooms.

\section{Study design and endpoints}

This mixed-method quasi-experimental before-after study evaluated the effect of introducing wearable ABHR dispensers, i.e. the intervention, by multiple measures. The main outcome was the observed $\mathrm{HH}$ compliance, defined as the proportion of individual $\mathrm{HH}$ indications met by a $\mathrm{HH}$ action [12]. Secondary outcomes were the measured consumption of $\mathrm{ABHR}$ and self-reported $\mathrm{HH}$ compliance. In addition, we investigated the perception and attitude of ED HCP regarding wearable dispensers by self-applied questionnaires and semi-structured interviews.

\section{Intervention}

The study consisted of a five-week baseline period and a seven-week intervention period that started with the introduction of wearable dispensers. The wearable dispenser (B Braun ${ }^{\oplus}, 100 \mathrm{ml}$, dimensions $7 \times 8 \times 2.2 \mathrm{~cm}$ ) included clips to attach the dispensers to the hospital apparel. Promotion of the wearable dispensers occurred in several staff-meetings, by user information via email, and by distribution of dispensers to HCP in person. The number and position of the mounted dispensers remained unchanged.

\section{Effect evaluation}

$\mathrm{HH}$ compliance, the main outcome parameter, was assessed according to the WHO 'My 5 moments for hand hygiene' observation method through direct observation by two trained and validated members of the IPC team (MD and JK) $[13,14]$. They recorded $\mathrm{HH}$ opportunities, $\mathrm{HH}$ actions, and HCP profession and sex in an anonymized form. During the last three weeks of the intervention period, the usage of either wearable dispensers or mounted dispensers was additionally noted during observations. Observations were done during weekdays at different time points between 8 am and 6 pm. Consumption of ABHR from mounted dispensers and wearable dispensers was assessed by weekly weighing the dispensers and counting the stock to calculate consumption. 
Perceived ABHR availability, self-reported HH compliance, and knowledge of the WHO 'My five moments for $\mathrm{HH}^{\prime}$ was assessed through a self-administered 3-item questionnaire using a 5-item Likert scale (Table 1). Additionally, participants indicated their profession and sex. Questionnaires were distributed to physicians' physical mailboxes and were made available in the nurses' common room after the baseline period and at the end of the intervention period.

\section{Sample size calculation and statistical analysis}

The needed number of $\mathrm{HH}$ opportunities in baseline and intervention was calculated on the assumption that $\mathrm{HH}$ at baseline would be $50 \%$, based on earlier observations using the same observation method. A clinically meaningful increase in $\mathrm{HH}$ compliance was judged to be at least 15 percentage points, i.e. from 50 to $65 \%$. Requiring equal sample sizes for baseline and intervention, and assuming an average cluster size of three, a two-sided alpha of 0.05 , and a power of $80 \%$ resulted in twice 339 opportunities.

Descriptive statistics were used to summarize data on $\mathrm{HH}$ compliance, ABHR consumption, and results of the questionnaire. Chi-square test was used to test differences in categorical variables. For comparison of continuous variables we used students t-test or anova, as appropriate. Multivariable logistic regression was used to adjust the

Table 1 Questionnaire for self-evaluation of participants

\begin{tabular}{ll}
\hline No. Question & Likert-Scale \\
\hline 1. Have you memorized the "WHO five moments for & $1=$ no \\
hand hygiene" so that you utilize them & $2=$ some of \\
automatically in daily routine? & $\begin{array}{l}\text { them } \\
3=\text { many of } \\
\text { them } \\
4=\text { most of } \\
\text { them }\end{array}$ \\
& $5=$ yes, \\
& completely \\
& $1=$ never \\
& $2=$ sometimes \\
2. How often do you correctly conduct hand & $3=$ often \\
hygiene according to the "WHO five moments for & $4=$ most of \\
hand hygiene"? & the time \\
& $5=$ always \\
& $1=$ never \\
& $2=$ sometimes \\
& $3=$ often \\
Is ABHR sufficiently available to conduct hand & $4=$ most of \\
hygiene according to the "WHO five moments for & the time \\
hand hygiene"? & $5=$ always \\
& \\
&
\end{tabular}

Abbreviations: $A B H R$ alcohol based hand rub, No. Number, WHO World Health Organisation effect of the intervention on $\mathrm{HH}$ compliance for potential confounders. We included the variables intervention period, sex, profession, hand hygiene moment and their respective subcategories in the multivariable model. We applied a chi-square test for trend to evaluate the change in consumption of ABHR from wearable dispensers as a proportion of overall ABHR consumption over time ('ptest', trend analysis for proportions). A $p$-value of $<.05$ was considered statistically significant. All statistical analysis were performed with STATA version 15 (Stata Corp., College Station, TX, USA).

\section{Semi-structured interviews and qualitative analysis}

Semi-structured interviews were conducted with a convenience sample of nurses and physicians working in the ED at the end of the intervention period. The interview guide is displayed in Table 2. All interviews were audio-taped after obtaining oral informed consent and transcribed verbatim. Data analysis of anonymized interviews was conducted inductively, following a grounded theory approach [15]. Two researchers (JK and AW) independently read transcripts and identified emerging themes. Emerging themes were then discussed and final categories were established through consensus. Quotes about barriers and facilitators were semi-quantified by a scoring system: three points for quotes mentioned by a majority of participants, two points for quotes mentioned by a minority but two or more, one point for quotes mentioned by a single participant.

\section{Results}

\section{Hand hygiene compliance}

A total of $811 \mathrm{HH}$ opportunities were observed, 328 (40.4\%) in the baseline period and 483 (59.6\%) in the intervention period. The average $\mathrm{HH}$ compliance rose from $56 \%$ during baseline to $64 \%$ during intervention with a univariable odds ratio of 1.36 (1.02-1.81; $p$ $=.035$ ). When adjusted for $\mathrm{HH}$ moment, sex and profession in the multivariable logistic regression model, odds ratio was $1.22(0.89-1.66 ; p=.218)$ (Table 3$)$. Weekly compliance across all indications are displayed in Fig. 1. In intervention, 7.3\% (95\% confidence interval (CI), 3.613.0) of observed $\mathrm{HH}$ actions were performed using wearable dispensers.

Table 2 Interview guide for the semi-structured interviews

\begin{tabular}{l} 
No. Question \\
\hline 1. What do you think of the recently introduced wearable dispensers? \\
2. How frequently have you used the wearable dispensers? \\
3. What are the advantages/disadvantages of the wearable \\
dispensers? \\
4. Are there any situations where you prefer using either the \\
5. Do you have ideas to improve the wearable dispensers?
\end{tabular}


Table 3 Univariable and multivariable analysis of predictors for hand hygiene compliance

\begin{tabular}{|c|c|c|c|c|c|c|}
\hline & \multicolumn{2}{|l|}{ Baseline period } & \multicolumn{2}{|c|}{ Intervention period } & \multirow{2}{*}{$\begin{array}{l}\text { Univariable } \\
\text { analysis } \\
\text { Odds ratio (C195\%) }\end{array}$} & \multirow{2}{*}{$\begin{array}{l}\text { Multivariable } \\
\text { analysis } \\
\text { Odds ratio (C195\%) }\end{array}$} \\
\hline & $\begin{array}{l}\mathrm{HH} \\
\text { opportunities }\end{array}$ & $\begin{array}{l}\mathrm{HH} \text { actions } \\
(\%)\end{array}$ & $\begin{array}{l}\mathrm{HH} \\
\text { opportunities }\end{array}$ & $\begin{array}{l}\mathrm{HH} \text { actions } \\
(\%)\end{array}$ & & \\
\hline $\begin{array}{l}\text { Intervention period (vs. baseline } \\
\text { period) }\end{array}$ & 328 & $185(56)$ & 483 & $308(64)$ & $1.36(1.02-1.81)$ & $1.22(0.89-1.66)$ \\
\hline \multicolumn{7}{|l|}{ WHO HH moment } \\
\hline Before touching patient & 87 & $31(36)$ & 106 & $39(37)$ & 1 & 1 \\
\hline Before aseptic procedure & 21 & $12(57)$ & 47 & $37(79)$ & $4.53(2.47-8.30)$ & $3.10(1.66-5.79)$ \\
\hline After body fluid exposure risk & 38 & $27(71)$ & 59 & $47(80)$ & $5.65(3.25-9.82)$ & $4.49(2.54-7.95)$ \\
\hline After touching patient & 162 & $109(67)$ & 254 & $180(71)$ & $4.00(2.79-5.73)$ & $4.05(2.80-5.86)$ \\
\hline $\begin{array}{l}\text { After touching patient } \\
\text { surroundings }\end{array}$ & 20 & $6(30)$ & 17 & $5(29)$ & $0.74(0.35-1.60)$ & $0.61(0.28-1.35)$ \\
\hline \multicolumn{7}{|l|}{ Sex } \\
\hline Female & 206 & $125(61)$ & 360 & $245(68)$ & 1 & 1 \\
\hline Male & 122 & $60(49)$ & 123 & $63(51)$ & $0.53(0.39-0.72)$ & $0.72(0.50-1.02)$ \\
\hline \multicolumn{7}{|l|}{ Profession } \\
\hline Physician & 114 & $57(50)$ & 156 & $74(47)$ & 1 & 1 \\
\hline Nurse & 210 & $128(61)$ & 313 & $224(72)$ & $2.18(1.62-2.95)$ & $1.92(1.34-2.76)$ \\
\hline Other & 4 & $0(0)$ & 14 & $10(71)$ & $1.33(0.51-3.46)$ & $0.93(0.34-2.51)$ \\
\hline
\end{tabular}

Abbreviations: $\mathrm{Cl}$ confidence interval, n.a. not applicable, $\mathrm{HH}$ hand hygiene

\section{Consumption of alcohol-based hand rub}

Figure 1 shows the weekly consumption of ABHR, which was $25.6 \mathrm{ml}$ per patient admission during baseline, and $25.2 \mathrm{ml}$ per patient admission during intervention. During the intervention period, $7.5 \%$ of the total ABHR consumption resulted from use of wearable dispensers, confirming the abovementioned $7.3 \%$ of observed use. Consumption of ABHR from wearable dispensers did increase over the seven-week intervention period $(p<.001)$.

\section{Perceived ABHR availability, self-reported hand hygiene compliance, and knowledge of $\mathrm{HH}$ moments}

A total of 87 questionnaires were returned, 51 during baseline (20 (39\%) by physicians, 27 (53\%) by nurses, and 4 (8\%) by others), and 36 during intervention (12 (33\%) by physicians, 22 (61\%) by nurses, and 2 (6\%) by others).

The perceived availability of ABHR did not increase from baseline to intervention (4.47 vs 4.64, $p=.31$ ). Self-reported $\mathrm{HH}$ compliance did not differ between baseline and intervention ( 4.12 vs $4.03, p=.56$ ), neither between sex (female vs male, 4.14 vs $3.97, p=.28$ ), nor profession (physician vs nurse vs other, 4.09 vs 4.08 vs $4.0, p=.96)$. Mean self-reported knowledge of $\mathrm{HH}$ indications did not differ between baseline and intervention (4.27 vs. 4.28, $p=.98$ ). Overall, women's perception of their own knowledge was better than men's (4.40 vs 4.03, $p=.024$ ), whereas profession had no impact on the self-reported knowledge (physician vs nurse vs others, 4.31 vs 4.29 vs $4.0, p=.61)$.

\section{Semi-structured interviews}

Overall, 24 participants took part in the interviews, 14 (58\%) nurses, nine physicians (38\%), and one (4\%) nursing assistant; six (25\%) participants were male. The interviews had a mean duration of $10 \mathrm{~min}$. Thirteen of the interviewees (54\%) had a negative overall impression of the wearable dispensers, eight $(33 \%)$ were neutral, and three $(13 \%)$ were positive.

We identified four categories of barriers and facilitators for the use of the wearable dispensers: usability characteristics of the current wearable dispenser, availability of ABHR, cues to action/cognition (i.e. subconscious or conscious activation towards use), and perceptions about the safetyof wearable dispensers. Selected typical interview quotes are listed in Table 4. A majority of facilitators was categorized to "availability". HCPs liked the principal idea of carrying the hand rub on them and also mentioned certain situations in which the wearable dispenser was of use, e.g. heading towards a patient from an area without mounted dispensers, and accompanying patient to wards where location of mounted dispensers was not familiar. In addition, interviewees perceived the wearable dispenser as a reminder to perform hand hygiene. Barriers were more often mentioned than facilitators, and arguments from all thematic groups emerged. Concerning usability, interviewees did not like the way the wearable dispensers were attached to the uniform because it made the dispenser dangle back and forth, and the fastening mechanism often 


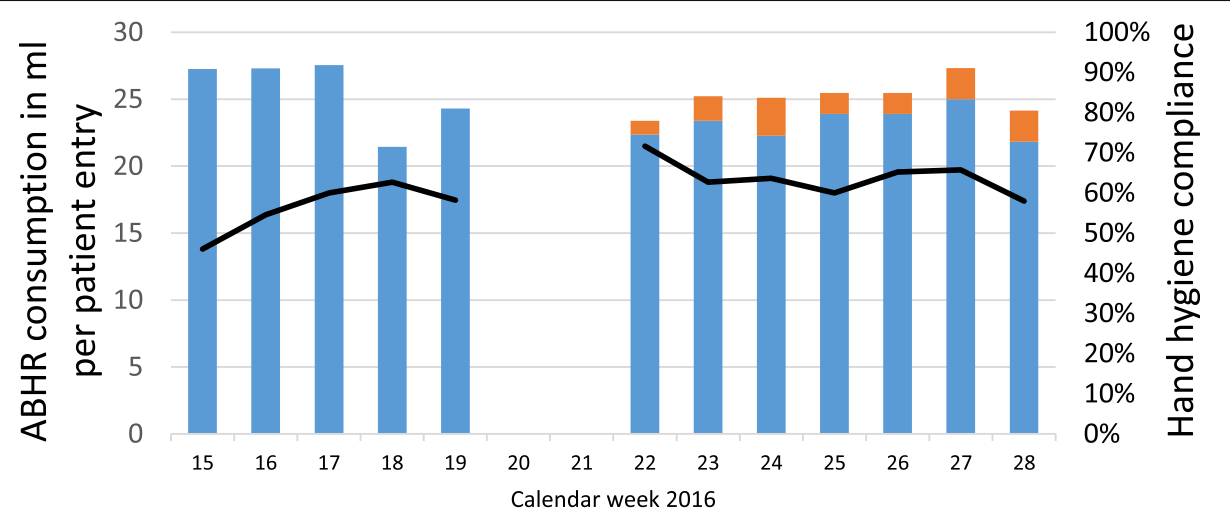

\section{Consumption from wearable dispensers \\ Consumption from mounted dispensers \\ - Observed HH Compliance (\%)}

Fig. 1 Hand hygiene compliance and consumption of alcohol based hand rub. Legend: The bar graph depicts consumption of ABHR in milliliters by mounted dispensers (blue bars) and wearable dispensers (orange bars). The line graph depicts HH compliance in percent. The five-week baseline period (weeks 15 to 19) and the seven-week intervention period (weeks 22 to 28) are separated by a two-week (weeks 20 and 21 ) period dedicated to preparing the intervention. Abbreviations: $\mathrm{ABHR}=$ Alcohol-based hand rub; $\mathrm{HH}=$ hand hygiene; $\mathrm{ml}=$ milliliters

failed, dropping the dispenser. HCP perceived the wearable dispensers as an additional item to carry around, while they already carried a multitude of other items such as stethoscopes and notes in their pockets, especially when wearing scrubs without coat. Wearable dispensers were mainly perceived to be unnecessary, given that a mounted dispenser was in easy reach during the vast majority of $\mathrm{HH}$ indications. HCPs were used to the mounted dispensers and habitually used them instead of the wearable dispensers. The outer surface of the wearable dispensers was perceived as risk factor for contaminating patients and hospital surroundings.

Interviewees made numerous suggestions about how to improve the wearable dispenser, including reducing its size to make it better fit in coat pockets, modifying the bottle outlet, e.g. by replacing it by a membrane, to avoid the need to open its cap, and improving the attaching mechanism.

\section{Discussion}

The purpose of this study was to examine whether a single intervention approach of introducing wearable ABHR dispensers in addition to existing mounted dispensers would increase observed $\mathrm{HH}$ compliance and ABHR consumption in our ED. Additionally, we aimed to explain the findings by qualitative and quantitative data on $\mathrm{HCP}$ perceptions and attitude. We found that the intervention did not improve $\mathrm{HH}$ compliance and consumption of ABHR. Less than a tenth of ABHR was consumed using wearable dispensers. Two main 'barriers' for the acceptance of the wearable dispensers explained this unexpectedly low uptake, namely the habitual use and perceived sufficient access to mounted dispensers and the flawed ergonomic design of the wearable dispensers.

Increasing availability of ABHR is an often-mentioned facilitator for $\mathrm{HH}$ compliance and the "WHO Guidelines on Hand Hygiene in Health Care" declare ABHR availability as a prerequisite for good $\mathrm{HH}$ compliance [16$18]$. Introducing wearable dispensers is one possibility to increase availability. Many researchers introduce wearable dispensers as part of multifaceted interventions. Yeung et al. found that the introduction of wearable dispensers with education led to increased $\mathrm{HH}$ compliance in long-term care facilities [10] and Koff et al. found improvement in $\mathrm{HH}$ compliance of anesthesia providers through the use of wearable dispensers with an audible alarm [19]. Only rarely introduction of wearable dispensers was studied as single intervention. Parks et al. were able to show that $\mathrm{HH}$ compliance of a regional anesthesia team increases when wearable dispensers are worn on person [20]. In contrast, the introduction of wearable dispensers in the ED of our hospital did not significantly increase $\mathrm{HH}$ compliance. Our results confirm the findings of Haas et al. in 2008, who did not find an improvement in ABHR consumption after introducing wearable dispensers in an ED [11].

Our ED is well equipped with mounted dispensers, making $\mathrm{ABHR}$ available within maximum $2 \mathrm{~m}$ distance from every patient bed. Interviewees mentioned the abundant availability of dispensers as one of the most important reasons for not using wearable dispensers and did not perceive an increase in availability of $\mathrm{ABHR}$ during intervention. Nevertheless, prior to this study, HCPs in the ED had repetitively been expressing the wish to get access to wearable dispensers. The low uptake in this investigation came therefore 
Table 4 Typical quotes about barriers and facilitators for use of wearable dispensers

\begin{tabular}{|c|c|c|}
\hline & Facilitators & Barriers \\
\hline \multirow[t]{12}{*}{ Usability } & Fastening mechanism $\bullet \circ \circ$ & Fastening mechanism $\bullet \bullet \bullet$ \\
\hline & \multirow{11}{*}{$\begin{array}{l}\text { - "I generally like the possibility to attach the wearable } \\
\text { dispensers to one's trousers." } \\
\text { - Dimensions } \bullet \circ \circ \\
\text { - "The size and weight of the wearable dispenser is perfect. If } \\
\text { it was bigger, it couldn't be put it in my pockets anymore." }\end{array}$} & $\begin{array}{l}\text { - "During a CT scan of a patient I accompanied, the wearable } \\
\text { dispenser came off four times." }\end{array}$ \\
\hline & & - "The wearable dispenser dangles constantly, and its weight \\
\hline & & pulls on my trousers which is really uncomfortable." \\
\hline & & Opening and closing mechanism $\bullet \bullet \circ$ \\
\hline & & - "It is difficult to close the bottle with one hand only." \\
\hline & & - Dosing of $A B H R \bullet \circ \circ$ \\
\hline & & $\begin{array}{l}\text { - "It is more difficult to dose the appropriate amount of ABHR } \\
\text { compared to wall-mounted dispensers" }\end{array}$ \\
\hline & & - Dimensions $\bullet \circ \circ$ \\
\hline & & $\begin{array}{l}\text { - "The wearable dispenser is so small that you have to } \\
\text { exchange it too often." }\end{array}$ \\
\hline & & Burden $\bullet \bullet \bullet$ \\
\hline & & $\begin{array}{l}\text { - "The wearable dispenser is just something more to carry } \\
\text { around, and I have to carry many other things with me } \\
\text { already." }\end{array}$ \\
\hline \multirow[t]{6}{*}{ Availability } & 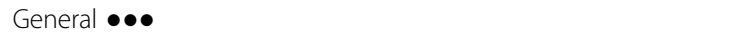 & 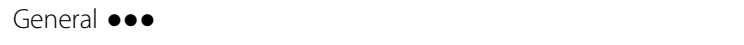 \\
\hline & $\begin{array}{l}\text { - "I generally like the idea that I carry the ABHR with me and } \\
\text { have it available all the time." }\end{array}$ & $\begin{array}{l}\text { - "No, I do not see any advantage of the wearable dispenser. We } \\
\text { do have enough ABHR available in the ER." }\end{array}$ \\
\hline & Specific situations $\bullet \bullet \circ$ & \\
\hline & $\begin{array}{l}\text { - "Sometimes the next wall-mounted dispenser is } 10 \mathrm{~m} \text { away, } \\
\text { then the wearable dispenser is of use." }\end{array}$ & \\
\hline & $\begin{array}{l}\text { - "I can use the wearable dispenser and do HH while heading } \\
\text { to a patient." }\end{array}$ & \\
\hline & $\begin{array}{l}\text { - "The wearable dispenser is of use, when I shift a patient to a } \\
\text { ward and do not know the locations of ABHR dispensers." }\end{array}$ & \\
\hline \multirow{4}{*}{$\begin{array}{l}\text { Cues to action / } \\
\text { Cognition }\end{array}$} & Habitualness $\bullet \circ \circ$ & Habitualness $\bullet \bullet$ \\
\hline & $\begin{array}{l}\text { - "Yes, I did use the wearable dispenser. I was used to } \\
\text { wearable dispensers from the hospital I worked before." }\end{array}$ & $\begin{array}{l}\text { - "I'm so used to all the wall-mounted dispensers... [that I did } \\
\text { not use the wearable dispenser]." }\end{array}$ \\
\hline & Reminder $\bullet \bullet \circ$ & \\
\hline & - "The wearable dispenser is a good reminder for $\mathrm{HH}^{\mathrm{H} .}$ & \\
\hline \multirow[t]{3}{*}{ Safety } & n.a. & Dispensers perceived as risk factor for contamination $\bullet \bullet \circ$ \\
\hline & & $\begin{array}{l}\text { - "The problem is that the bottle has to be opened with } \\
\text { contaminated hands and afterwards closed with clean hands." }\end{array}$ \\
\hline & & $\begin{array}{l}\text { - "The dirty bottle in contact with my clean clothes all the } \\
\text { time." }\end{array}$ \\
\hline
\end{tabular}

Abbreviations: $A B H R$ alcohol based hand rub, CT Computer tomography, ER emergency room, $H H$ hand hygiene, $\bullet \bullet \bullet$ Mentioned by a majority of participants. $\bullet \bullet$ Mentioned by $\geq 2$ participants. $\bullet \circ \circ$ Mentioned by one single participant

as a surprise. Interviewees did not comment on the ED's anecdotal wish for wearable dispensers, but we hypothesize that it was voiced mainly by HCPs who were used to wearable dispensers from other hospitals or was triggered by rare events where ABHR was not accessible, corresponding to a classical reporting bias. Yet, interviewees identified two situations where ABHR was not easily accessible: first, when approaching a patient from a non-patient area in the ED such as the central working station or the meeting room and second, when accompanying patients to locations with unfamiliar localization of mounted dispensers.
Poor usability of the wearable dispensers was seen as a main barrier for application and several HCP interviewees expressed safety concerns as the outer surface of the dispensers was perceived to contaminate clean hands and patients surroundings. The design of a medical device affects compliance and behavior. Human factors engineering principles like 'affordance' (i.e. making use intuitive) and 'minimizing physical effort' (i.e. making adherence convenient) were found to improve adherence when applied in the development of medical devices [21, 22]. Good usability of medical products was shown to improve patient safety, e.g. 
by reducing errors using blood glucose meters and increase compliance using hand sanitizers [23, 24]. Properties of a medical product can act as 'forcing functions'. These 'forcing functions' limit user errors by prohibiting or facilitating specific actions, and stand at the top of scale of the 'hierarchy of intervention effectiveness' - structural and technological interventions are more reliable in shaping people's behavior than human based interventions such as training and education [25]. Therefore, the wearable dispensers might benefit from an optimized design to encourage use and dismantle safety concerns.

Our study has limitations. First, the intervention period might have been too short to change a year-long habit. Second, although we were not aware of any other infection prevention and control promotional activity in the ER during the study periods we cannot fully exclude a time dependent bias. Third, as we only provided wearable dispensers to the ED staff and not to healthcare providers 'visiting' the ER (e.g. consultation service), the percentage of consumption from wearable dispensers might have been underestimated. Still, the amount of ABHR consumed by 'visiting' HCP is probably negligible. Forth, the Hawthorne effect and $\mathrm{HH}$ observation only during daytime, excluding night-shifts and weekends, might have skewed the $\mathrm{HH}$ observation results. Our results were, however, triangulated by ABHR consumption and the qualitative and quantitative investigation of perception and attitude of ED collaborators, which are strengths of the mixed-method study approach we used [26].

\section{Conclusion}

In conclusion, we found that the a single intervention of introduction of wearable ADHR dispensers in a busy $E D$, that had already been well equipped with mounted ABHR dispensers, did not significantly improve hand hygiene compliance or ABHR consumption. The main barriers for their use according to HCPs were the competing benefit of well-placed and abundant mounted dispensers and the flawed ergonomic design.

\section{Abbreviations \\ ABHR: Alcohol-based hand rub; Cl: Confidence interval; ED: Emergency Department; HCP: Healthcare provider; HH: Hand Hygiene; IPC: Infection prevention and control; UHZ: University Hospital Zurich; WHO: World health organization}

\section{Acknowledgements}

We would like to acknowledge the contribution of the health care providers of the Emergency Department of the University Hospital Zurich, Switzerland, who took part in the study.

\section{Funding}

This study was partially funded by the Swiss National Science Foundation, grant 32003B_149474.

AW is supported by the academic career program "Filling the gap" of the Medical Faculty of the University of Zurich.

300 Clips for attaching the wearable dispensers were sponsored by B Braun, Switzerland.

\section{Availability of data and materials}

The datasets used and/or analyzed during the current study are available from the corresponding author on reasonable request.

\section{Authors' contributions}

JK, YF, HS, LC and AW designed the study. JK, YF, MD acquired the data, and $J K, A W$, and SPK performed the statistical analysis. JK, AW, and LC performed qualitative analysis of the interviews. AW, JK, LC, and HS analyzed and interpreted the data. JK and AW drafted the manuscript, and HS, LC, SPK, YF, $D E, D I K$ and MD provided critical review of the manuscript for important intellectual content. All authors agree with the content and conclusions of this manuscript.

Ethics approval and consent to participate

Not applicable.

\section{Consent for publication}

Not applicable.

\section{Competing interests}

The authors declare that they have no competing interests.

\section{Publisher's Note}

Springer Nature remains neutral with regard to jurisdictional claims in published maps and institutional affiliations.

\section{Author details}

'Division of Infectious Diseases and Hospital Epidemiology, University Hospital Zurich, University of Zurich, Rämistrasse 100, CH-8091 Zurich, Switzerland. ${ }^{2}$ Emergency Department, University Hospital Zurich, University of Zurich, Zurich, Switzerland. ${ }^{3}$ Baraka Health Centre, German Doctors Nairobi, Nairobi, Kenya.

Received: 12 September 2018 Accepted: 14 November 2018

Published online: 23 November 2018

\section{References}

1. Zimlichman $\mathrm{E}$, et al. Health care-associated infections: a meta-analysis of costs and financial impact on the US health care system. JAMA Intern Med. 2013;173(22):2039-46.

2. Pittet $\mathrm{D}$, et al. Evidence-based model for hand transmission during patient care and the role of improved practices. Lancet Infect Dis. 2006; 6(10):641-52.

3. Allegranzi B, Pittet D. Role of hand hygiene in healthcare-associated infection prevention. J Hosp Infect. 2009:73(4):305-15.

4. WHO. Guide to implementation: a guide to the implementation of the WHO Multimodal Hand Hygiene Improvement Strategy. 2009 [cited 2018 Jan 14]; Available from: http://www.who.int/gpsc/5may/Guide_to_ Implementation.pdf.

5. Erasmus V, et al. Systematic review of studies on compliance with hand hygiene guidelines in hospital care. Infect Control Hosp Epidemiol. 2010; 31(3):283-94.

6. Scheithauer $S$, et al. Improving hand hygiene compliance in the emergency department: getting to the point. BMC Infect Dis. 2013;13:367.

7. Pittet $D$, et al. Hand hygiene among physicians: performance, beliefs, and perceptions. Ann Intern Med. 2004;141(1):1-8.

8. Goodliffe L, et al. Rate of healthcare worker-patient interaction and hand hygiene opportunities in an acute care setting. Infect Control Hosp Epidemiol. 2014;35(3):225-30

9. Pittet $\mathrm{D}$, et al. Effectiveness of a hospital-wide programme to improve compliance with hand hygiene. Infection Control Programme Lancet. 2000; 356(9238):1307-12.

10. Yeung WK, Tam WS, Wong TW. Clustered randomized controlled trial of a hand hygiene intervention involving pocket-sized containers of alcoholbased hand rub for the control of infections in long-term care facilities. Infect Control Hosp Epidemiol. 2011;32(1):67-76.

11. Haas JP, Larson EL. Impact of wearable alcohol gel dispensers on hand hygiene in an emergency department. Acad Emerg Med. 2008;15(4):393-6.

12. Sax $\mathrm{H}$, et al. The World Health Organization hand hygiene observation method. Am J Infect Control. 2009;37(10):827-34. 
13. WHO. In WHO Guidelines on Hand Hygiene in Health Care. Geneva: First Global Patient Safety Challenge Clean Care Is Safer Care; 2009.

14. Sax H, et al. My five moments for hand hygiene': a user-centred design approach to understand, train, monitor and report hand hygiene. J Hosp Infect. 2007;67(1):9-21.

15. Strauss AL, Corbin JM. Grounded theory in practice. Thousand Oaks: Sage Publications; 1997.

16. Hugonnet S, Perneger TV, Pittet D. Alcohol-based handrub improves compliance with hand hygiene in intensive care units. Arch Intern Med. 2002;162(9):1037-43.

17. Picheansathian W. A systematic review on the effectiveness of alcoholbased solutions for hand hygiene. Int J Nurs Pract. 2004;10(1):3-9.

18. WHO Guidelines on Hand Hygiene in Health Care - First Global Patient Safety Challenge Clean Care is Safer Care. WHO 2009. http://apps.who.int/iris/ bitstream/10665/44102/1/9789241597906 eng.pdf. Last Accessed 24 Feb 2018.

19. Koff MD, et al. Reduction in intraoperative bacterial contamination of peripheral intravenous tubing through the use of a novel device. Anesthesiology. 2009;110(5):978-85.

20. Parks $C L$, Schroeder KM, Galgon RE. Personal hand gel for improved hand hygiene compliance on the regional anesthesia team. J Anesth. 2015;29(6): 899-903.

21. Drews FA, Bakdash JZ, Gleed JR. Improving central line maintenance to reduce central line-associated bloodstream infections. Am J Infect Control. 2017:45(11):1224-30.

22. Drews FA. Adherence engineering. a new approach to increasing adherence to protocols Ergon Des. 2013;21:19-25.

23. Cure L, Van Enk R. Effect of hand sanitizer location on hand hygiene compliance. Am J Infect Control. 2015;43(9):917-21.

24. Rogers WA, Mykityshyn AL, Cambell RH, Fisk AD. Analysis of a "simple" medical device. Ergon Des. 2001;9(1):6-14.

25. Cafazzo, J.A. and O. St-Cyr, From discovery to design: the evolution of human factors in healthcare. Healthc Q, 2012. 15 Spec No: p. 24-29.

26. Jick TD. Mixing qualitative and quantitative methods - triangulation in action. Adm Sci Q. 1979;24(4):602-11.

Ready to submit your research? Choose BMC and benefit from:

- fast, convenient online submission

- thorough peer review by experienced researchers in your field

- rapid publication on acceptance

- support for research data, including large and complex data types

- gold Open Access which fosters wider collaboration and increased citations

- maximum visibility for your research: over $100 \mathrm{M}$ website views per year

At $\mathrm{BMC}$, research is always in progress.

Learn more biomedcentral.com/submissions 